\title{
Mineral Raw Materials' Resource Efficiency in Selected ESEE Countries: Strengths and Challenges ${ }^{\dagger}$
}

\author{
Stavroula Giannakopoulou ${ }^{1, *(\mathbb{D}}$, Fotini Chalkiopoulou ${ }^{2}$ and Katerina Adam ${ }^{1}(\mathbb{D}$ \\ 1 School of Mining and Metallurgical Engineering, National Technical University of Athens (NTUA), \\ 15780 Athens, Greece; katadam@metal.ntua.gr \\ 2 Department of Mineral Processing, Hellenic Survey of Geology and Mineral Exploration (HSGME), \\ 13677 Acharnae, Greece; fchalkiopoulou@igme.gr \\ * Correspondence: gianstav@metal.ntua.gr; Tel.: +30-21-0772-4482 \\ + Presented at International Conference on Raw Materials and Circular Economy, Athens, Greece, \\ 5-9 September 2021.
}

check for

updates

Citation: Giannakopoulou, S.; Chalkiopoulou, F.; Adam, K. Mineral Raw Materials' Resource Efficiency in Selected ESEE Countries: Strengths and Challenges. Mater. Proc. 2021, 5, 83. https://doi.org/10.3390/ materproc2021005083

Academic Editor: Evangelos Tzamos

Published: 21 December 2021

Publisher's Note: MDPI stays neutral with regard to jurisdictional claims in published maps and institutional affiliations.

Copyright: (c) 2021 by the authors. Licensee MDPI, Basel, Switzerland. This article is an open access article distributed under the terms and conditions of the Creative Commons Attribution (CC BY) license (https:// creativecommons.org/licenses/by/ $4.0 /)$.

\begin{abstract}
The mineral raw materials' resource efficiency is currently recognized in Europe as the way for the future development of the European mining economies. With this aim, a West Balkan Mineral Register was created in the EIT Raw Materials RESEERVE Project, including Primary and Secondary Raw Materials of six Eastern and South-Eastern Europe (ESEE) countries, i.e., Albania, Bosnia and Herzegovina, Croatia, Montenegro, North Macedonia, and Serbia. Within the Project, a Strengths, Weaknesses, Opportunities, and Threats (SWOT) and Gap Analysis was also performed for the development of the raw material sector in the region. This paper summarizes the main strengths to be exploited, i.e., the significant geological potential, the presence of critical raw materials (e.g., $\mathrm{Sb}$, $\mathrm{Co}, \mathrm{REEs}$ ) in primary and secondary raw materials, and the challenges to address, i.e., compliance of resources/reserves classification with international standards, integration of state's mineral policy with spatial planning strategies, improvement of the business environment, capacity building of the raw materials workforce and enhancement of the public acceptance of the sector, in order to achieve the sustainable development of the mineral resources of the six ESEE countries. These opportunities comply with the objectives of the EU Raw Materials Initiative and are expected to contribute in the further enhancement of those economies in transition for the upcoming years.
\end{abstract}

Keywords: mineral raw materials; mineral resource efficiency; geological potential; sustainability; primary raw materials; secondary raw materials; critical raw materials; ESEE region

\section{Introduction}

As emphasized in the EC Raw Materials Initiative (RMI), raw materials are essential for the sustainable functioning of Europe's industries and, in a broader context, of Europe's economy and society [1]. Moreover, improved efficiency of mineral resources is an essential aspect of resource efficiency [2].

At a European level, a positive environment for investments in the raw materials sector and a political will for re-industrialization are observed. This is mainly due to the strong presence of other countries such as China, Russia, and USA at the world trade of mineral raw materials and the low EU's mineral raw materials production, posing strategic risks to the EU's supply, and future industrial development [1]. The unique geological potential of primary raw materials (PRMs) in the ESEE Region with a great percent being mined and the presence of secondary raw materials (SRMs), results in the high relevance of the ESEE region with the European commodity strategy [3].

This issue has been addressed in a number of recent EU-funded research projects, e.g., SARMA [4], RIS-RESTORE [5], and RESEERVE [6], whose findings evidence that the main factors affecting the sustainable exploitation and management of mineral resources in ESEE 
countries include the prevailing mineral policies, land use planning, permitting procedures and stake holders involvement, exploitation of secondary resources, and geological data management.

Within this framework, and during the implementation of the RESEERVE Project, a SWOT/Gap Analysis was performed for the development of the raw material sector in the ESEE Region. This paper presents the strengths to be exploited and the challenges that the six examined ESEE countries, i.e., Albania, Bosnia and Herzegovina, Croatia, Montenegro, North Macedonia and Serbia, need to address in order to achieve mineral raw materials resource efficiency.

\section{Methodology}

The SWOT analysis performed within the RESEERVE Project [7] aimed to identify and group the main strengths, weaknesses, opportunities, and threats of the raw materials sector, in the 6 ESEE countries examined. In addition, the gap analysis presented the barriers and obstacles (legislative, regional, technological, etc.) encountered for the development of the sector. The main areas examined in the SWOT/Gap Analysis included: geological potential; economic environment; legal and regulatory framework; innovation and technological framework; environmental protection and land use planning; government and societal potential and human resources, and educational potential.

In the present article, the key strengths of the 6 ESEE countries, i.e., the geological potential of primary raw materials (PRMs) and secondary raw materials (SRMs) and the presence of critical raw materials (CRMs) are summarized.

Then, key challenges to be addressed and gaps to be covered in order to achieve resource efficiency and enhance the development of the raw material sector in the region, are given, including the quality of the geological data, reforms in the mining and quarrying legal framework, improvements in the countries business environment and human resources capacity building.

Data presented in the article regarding geological potential of deposits were based on the West Balkan Mineral Register [6], the database created within the RESEERVE Project, for primary and secondary raw materials in compliance with the INSPIRE Guidelines for Mineral Resources [8]. Other information presented in this paper are based on the deliverables of the RESEERVE Project D6.1 [9], D6.2 [10], as well as open data and international reports on the business performance [11], and mineral production of the 6 ESEE countries [12,13].

\section{Results}

\subsection{Key Strength: Geological Potential}

Based on the RESEERVE West Balkan Mineral Register database [6], and the data evaluation performed within the project, the main business opportunities regarding raw materials identified in the 6 ESEE countries are summarized, below:

\subsubsection{Primary Raw Materials of Albania}

Albania (ALB) owns metallic PRMs of the iron-ferro alloy group, mainly chromite and iron-nickels, as well as copper ores and Ti, the latter included in the CRMs list of Europe 2020 [14]. All chromite ore deposits recorded in the RESEERVE Register [6] are currently exploited in underground mines, almost half of them located in the municipality of Bulqizë. Albania's geological potential of chromium ore, mostly found in small to medium sized deposits (15 Mt Proved and $2 \mathrm{Mt}$ Proved and Probable ore reserves), is significant for the country's economy and the production of Chromium for 2019 was $488,700 \mathrm{t}$ as $\mathrm{Cr}_{2} \mathrm{O}_{3}$ Content [12]. Major metallic PRMs of ALB also include small to medium sized Fe and Fe-Ni deposits (162 Mt Proved and $58 \mathrm{Mt}$ Proved and Probable ore reserves), and medium to large $\mathrm{Cu}$ ore deposits of $25 \mathrm{Mt}$ Proved ore reserves, some containing Au. Regarding non-metallic PRMs, ALB's potential is rather moderate. However, emphasis is placed on phosphate rocks included in the CRMs list of Europe 2020 [14], with resources estimated 
to $12 \mathrm{Mt}$. It is finally noted that ALB's mineral resources and reserves have not yet been classified with a national classification standard or international code, i.e., JORC [15].

\subsubsection{Primary Raw Materials of Bosnia and Herzegovina}

Bosnia and Herzegovina $(\mathrm{BiH})$ is the major, among the six ESEE countries, bauxite producer with an annual production averaging $1 \mathrm{Mt}$. There is a number of bauxite deposits in the country, including large deposits in operating mines, small deposits of $34 \mathrm{Mt}$ Probable ore reserves and other deposits whose size and reserves are not yet reported. A number of medium to very large sized Fe-ore deposits of $130 \mathrm{Mt}$ (either Proved or Probable reserves) are also recorded in $\mathrm{BiH}$, with an iron (Fe-content) production of 739,600 $\mathrm{t}$ in 2019 [12]. Lead, zinc and lead-zinc ores also occur as large and very large deposits, including Greenfields projects and mines under development. Precious and rare metals like Ag, Ge, and Ga are contained in some lead-zinc ores, while mining an Au ore deposit is under development. $\mathrm{BiH}$ owns significant non-metallic PRMs potential including bentonite and fire clays, gypsum, kaolinite, magnesite and salt, zeolites, quartz, aggregates and dimension stones. As reported by WMD [12], in 2019 the production of industrial minerals (bentonite, gypsum, kaolinite, magnesite and salt) was 1,414,004 t.

\subsubsection{Primary Raw Materials of Croatia}

In Croatia (HRV) aluminum mineralization has been reported, in the form of boehmite in many small sized bauxite deposits, mostly not exploited, containing CRM, i.e., Ti, V, $\mathrm{Ga}$. Resources and reserves of above commodities are to be estimated in order to update the West Balkan Mineral Register database [6]. Significant non-metallic mining activity is observed in the field of aggregates, with many calcite and quartz sand deposits of interest for the chemical and other industries, as well as gypsum. Ore reserves classification in compliance with international standards needs to be conducted in HRV [16].

\subsubsection{Primary Raw Materials of Montenegro}

Montenegro (MNE) presents medium to large and very large $\mathrm{Pb}$ - $\mathrm{Zn}$ deposits of 53.6 Mt Proved ore reserves and the relevant sector is developing with five Greenfields areas at the feasibility stage. MNE is also the second most important bauxite producer among the six ESEE countries examined with an annual production of 774,725 $t$ for 2019 [12]. Small sized bauxite deposits of $24 \mathrm{Mt}$ Proved and $6 \mathrm{Mt}$ Probable ore reserves in operating and under development mines were reported in the RESEERVE Register. Further, 7.4 Mt of Probable $\mathrm{Cu}$ ore reserves were recorded. The non-metallic PRM potential of MNE is rather low, mainly including aggregates extraction [6]. For the classification of resources/reserves in types the Russian State Committee on Reserves (GKZ) system is applied in MNE.

\subsubsection{Primary Raw Materials of North Macedonia}

North Macedonia (MKD) is rich in valuable and rare metallic PRMs, with some of them included in the CRMs list [14], e.g., Sb in Lojane and Alšar, the Mitrašinci Ti-Fe ore containing $3-12 \% \mathrm{TiO}_{2}$, of unknown reserves, the Mo in the Greenfields area of Strelci, currently at the stage of feasibility study, and the Mo-Cu-Au ore at Petrošnica of unknown reserves. High $\mathrm{Cu}$ mineralization potential mainly of porphyry type is encountered, in the form of very large deposits of $734 \mathrm{Mt}$ Proved and Proved and Probable ore reserves, with most of them under development (e.g., Ilovica, Plavica and Crn Vrv, Borov Dol, Kazan Dol, etc.). MKD's annual Cu production ranged from 11,000 $\mathrm{t}$ in 2015 to $7231 \mathrm{t}$ in 2019 [12]. $\mathrm{The} \mathrm{Pb}-\mathrm{Zn}$ sector also presents a high potential with large to very large deposits of $28 \mathrm{Mt}$ mostly Proved ore reserves in five areas. Lead production ranged from 37,920 t in 2015, to $43,490 \mathrm{t}$ in 2019, while the $\mathrm{Zn}$ annual production remains stable at around 30,000 $\mathrm{t}$ [12]. MKD is also producing $\mathrm{Au}$ and $\mathrm{Ag}$ (593 kg and 17,780 kg, respectively, for 2019) [12]. Other metallic PRMs such as Fe-Ni ore deposits are reported, including the very large deposit of Rakle of $200 \mathrm{Mt}$ at feasibility stage. For ore reserves classification no international standard is applied in MKD. 


\subsubsection{Primary Raw Materials of Serbia}

Serbia (SRB) is also rich in valuable metallic PRMs, including precious metals and PGEs. Bor consists the most significant metallogenic zone in the country and West Balkans in general, where more than $650 \mathrm{Mt}$ of $\mathrm{Cu}$ ore corresponding to $4.93 \mathrm{Mt}$ of $\mathrm{Cu}$ and $280 \mathrm{t}$ of $\mathrm{Au}$, were produced since 1902 [17]. Large and very large $\mathrm{Cu}$ deposits are mainly hosted in Bor area, with $\mathrm{Cu}$ ore resources of $4000 \mathrm{Mt}$. Other areas hosting very large $\mathrm{Cu}$ deposits are the municipalities of Majdanpek, Medveđa and Žagubica, thus increasing total Probable and Proved reserves, per almost $1000 \mathrm{Mt}$. Gold is found in many of the above deposits, while the sites of Korkan and Bigar Hill consist of two sediment-hosted Au mineralization deposits of unknown reserves type. Čukaru Peki presents a great potential and is ranked among the most important $\mathrm{Cu}$ and Au deposits, in a global scale [17]. Other deposits presenting high potential as business opportunities are the very large Li-Borates ore deposit, (135.7 Mt of Proved and Probable reserves), and a Mo ore deposit (177 Mt of Proved and Probable reserves), both currently under development by inward investments. However, and despite the very significant geological potential of SRB, mineral production of 2019 [12] remained at low levels. To mitigate the above, there is a very strong interest expressed for new mining projects by international investors as reported by European Bank for Reconstruction and Development (EBRD) [18].

\subsubsection{Secondary Raw Materials in the ESEE Region}

Potential secondary raw materials resources in the ESEE Region, consist of mining and processing wastes (SRMs) occupying total surface area of $5892 \mathrm{Ha}$, corresponding to 1461 waste sites. The majority of these sites, 1371 of 1461 , i.e., $94 \%$, concerns mining waste landfills occupying an area of $3308.26 \mathrm{Ha}$, i.e., $>50 \%$ of the overall waste disposal area. The remaining sites consist of flotation tailings, red mud dams and slag/ash landfills and present high interest for the recovery of the contained valuable metals (for example $\mathrm{Au}, \mathrm{Cr}$, $\mathrm{Cu}, \mathrm{REEs})$. Reprocessing of these wastes could be further examine $\mathrm{d}$ following the metal reserves estimation. Waste management and SRMs exploitation comprise key component of resource efficiency and a prerequisite for the future development of the mining sector in the region.

\subsubsection{Critical Raw Materials in the ESEE Region}

A number of the PRMs and SRMs listed in the previous paragraphs are included in the CRM list of Europe 2020 [14]. These correspond to Albanian phosphate rocks and Ti, bauxites in $\mathrm{BiH}, \mathrm{MNE}$ and $\mathrm{HRV}$, including elements such as $\mathrm{Ge}, \mathrm{Ga} \mathrm{Ti}, \mathrm{V}, \mathrm{Sb}$ and Mo ore deposits found in MKD. All CRM sites in the 6 ESEE countries are presented in the Map of Figure 1, created with ArcGIS 10.5.1 [9].

\subsection{Key Challenges}

Based on the overall SWOT and Gap analysis, regarding the factors impacting the development of the raw material (RM) sector, key challenges for the six ESEE countries, i.e., major fields that need improvement, were defined as follows:

- Upgrading the quality of geological potential data;

- Promoting legislation reforms and codification;

- Improving the business environment, and

- Human resources capacity building.

\subsubsection{Upgrading the Quality of Geological Potential Data}

As highlighted in the RESEERVE project, a prerequisite for the development of a PRM or SRM resource as a business opportunity is to identify and quantify the resources type, (inferred, indicated, measured), or/and reserves' type of a deposit, (probable, proved), for all the commodities of interest. All six ESEE countries examined present digital databases, including geological potential data. However, in order to enhance the visibility of a mining project and attract national or international funding, reporting exploration results, 
mineral resources and ore reserves, estimation of resources or reserves should be performed in compliance with international codes and standards, like JORC, PERC, CIM, etc. As already noted, identification of mineral resources and characterization of reserves as per the INSPIRE Directive [8] was an important project objective completed with the RESEERVE West Balkan Mineral Register [6]. To this end, the PRM Register could be further developed to include data for the reserves of other commodities contained in the deposits, including REEs. Thus, additional exploration work may be required for certain PRMs to increase the confidence level of existing geological data and estimate reserves per commodity.

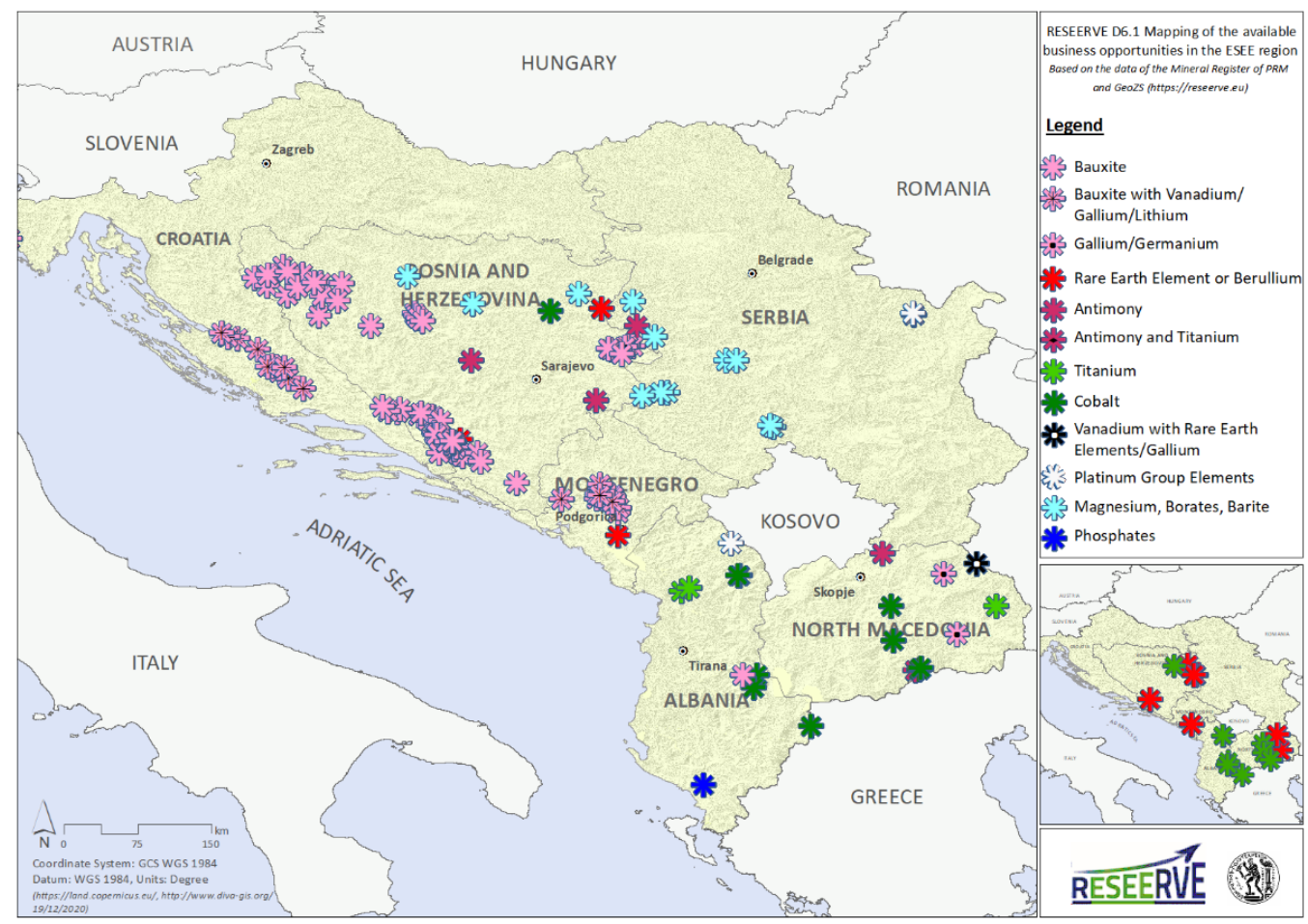

Figure 1. CRM presence in PRM and selected SRM sites of the 6 ESEE countries.

\subsubsection{Promoting Legislation Reforms and Codification}

All six ESEE countries reported legislation reforms in the last years, including regulations to enhance business environment, in agreement with the findings of the World Bank Doing Business report issued in 2011 for the ESEE Region.

Moreover, in order to circumvent legal constrains, axes for interventions include: state's mineral policy and strategy; exploration and exploitation licensing and permitting procedures - competencies; royalties/fees and compensatory benefits; harmonization of spatial plans, and alignment with the EU environmental legislation. In addition to reforms and updates in the above areas, codification of the M\&Q regulations and the simplification of regulations, is necessary in order to enhance the RM sector performance.

\subsubsection{Improving Business Environment}

To assess business environment, the overall ease of doing business indicator (DB20) set by World Bank was examined, taking into account the following ten (10) sub indicators: starting a business, dealing with construction permits, getting electricity, registering property, getting credit, protecting minority investors, paying taxes, trading across borders, enforcing contracts, and resolving insolvency.

In the scores from 1-100 for three out of the ten indicators, namely starting a business, dealing with construction permits and enforcing contracts, as well as the overall DB20, are presented for the six ESEE countries examined in the RESEERVE Project. In the same diagram (Figure 2), scores of the same indicators for the EU countries Finland (Fl), 
Germany (DE), France (FR), Czech Republic (CZ) and Greece (EL), and Canada (CAN), a major international RM producer, were also included for comparison purposes.

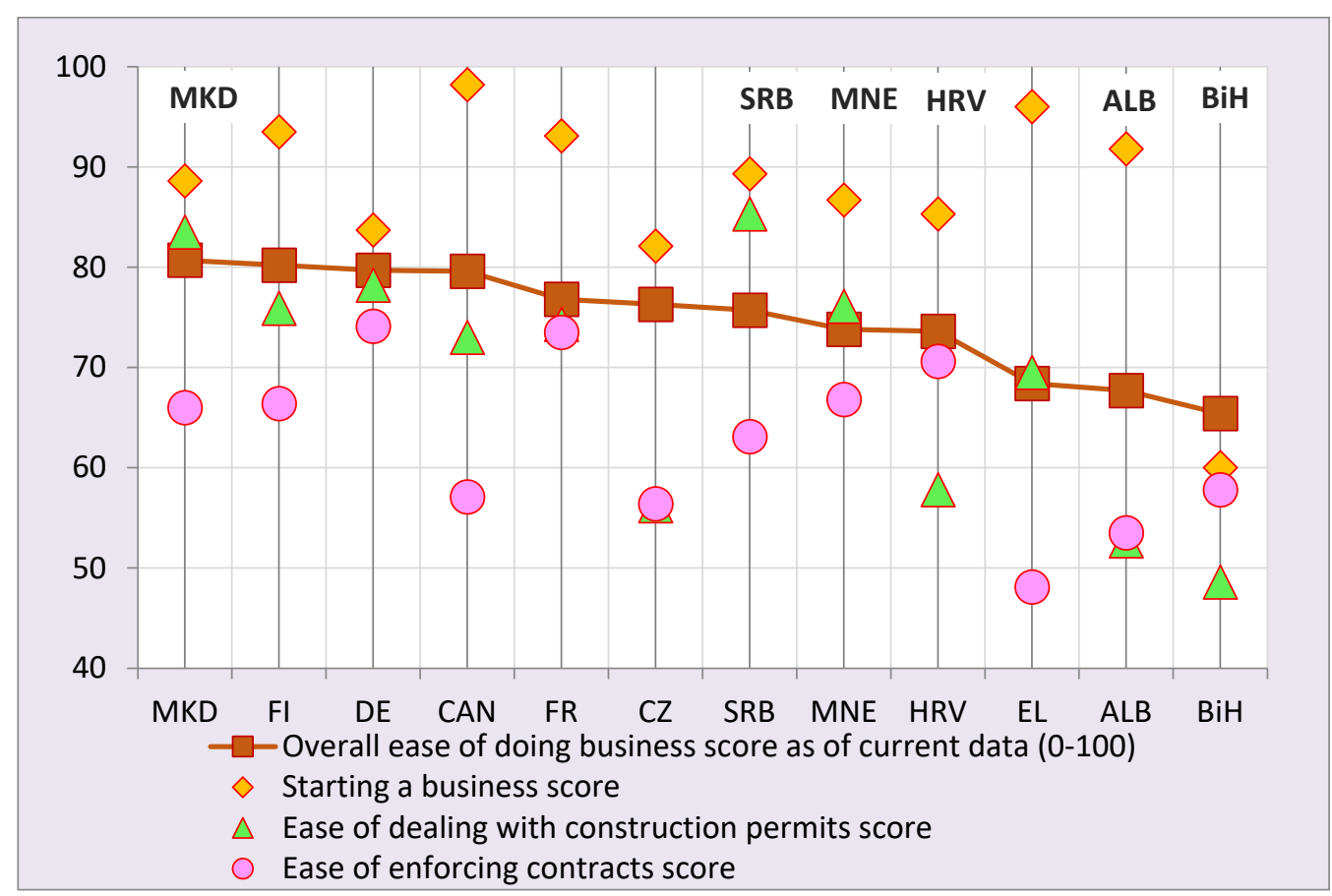

Figure 2. Comparison of the overall ease of doing business score (DB20) and the values of 3 selected indicators, [11] of the 6 ESEE countries and Finland (Fl), Germany (DE), Canada (CAN), France (FR), Czech Republic (CZ), Greece (EL).

From the above analysis, and the evaluation of available data, it is deduced that:

- The six ESEE economies have implemented reforms improving their business regulations during the period 2008-2020, with MKD reported as a top performer, and currently presenting the most favorable business environment among the six ESEE countries. The overall ease of doing business score of the six ESEE countries is comparable to that of a number of EU countries.

- $\quad$ Starting a business seems to be very easy in SRB, MNE, HRV and ALB, scores ranging between 65.7 and 75.7. However, additional regulation reforms are needed in order to improve ease of dealing with construction permits for HRV and ALB and ease of enforcing contracts mainly for SRB and ALB. Starting a business and dealing with construction permits is reported as still difficult in $\mathrm{BiH}$ ranked in the last places when compared with the economies of the other ESEE countries examined for these two individual indicators set by World Bank.

- Ease of getting credit, an important indicator for business development, needs to be further improved in SRB, HRV and $\mathrm{BiH}$.

\subsubsection{Human Resources Capacity Building}

The need to strengthen the skills of technical, scientific and managerial personnel involved in the overall spectrum of RM activities, including research, exploration, mining, processing, recycling and environmental management, is a common conclusion among the six ESEE countries. Reduced availability of skilled professionals and technical staff due to brain drain or other reasons (e.g., limited interest of students in the field of geology and the RM sector in general) and limited expertise on new technologies on exploration, extraction and processing of minerals and wastes, are some of the areas of concern reported by the stake holders. Gaps were also noted in the related educational programs as compared with the present and evolving needs of the RM sector. Limited cooperation between academia, research and technology organizations (RTOs), and industry was also identified 
as a challenge. Capacity building programs are needed for the training of scientists and technical staff, given the increased emerging needs of the RM sector in the region. From the six ESEE countries examined Croatia is already an active partner in the European Institute of Innovation and Technology, Regional Innovation Scheme, (EIT RIS) projects. Croatian Universities, e.g., University of Zagreb and other partners from the Knowledge Triangle of the 6 ESEE Countries coordinate and participate in EIT raw materials programs, aiming to increase innovation, entrepreneurship along the raw materials sector. Moreover, almost all countries expressed their interest for further participation in EIT raw materials projects and cooperation with international institutes, and organizations.

\section{Conclusions}

For all the six ESEE countries examined within the RESEERVE Project, i.e., Albania, Bosnia and Herzegovina, Croatia, Montenegro, North Macedonia, and Serbia, major strength for the sustainable development of the raw material sector are related to their geological potential and the presence of PRMs and SRMs, in a number of metallic commodities, their geographic location and their long tradition in mining. These commodities include aluminum $(\mathrm{Al})$ antimony $(\mathrm{Sb})$, chromium $(\mathrm{Cr})$, copper $(\mathrm{Cu})$, lead $(\mathrm{Pb})$, zinc $(\mathrm{Zn})$, precious metals $(\mathrm{Ag}, \mathrm{Au})$, mineral fuels, industrial minerals and building materials. There is also a number of CRMs, like bauxites and the contained REEs (BiH, MNE, HRV) and Co, Sb and Ti (ALB, MKD). Regarding SRMs a high potential for reprocessing and recovery of valuable metals in flotation tailings of copper and lead-zinc was recorded. Additionally, recovery of CRM rare earths from red mud constitutes an opportunity to be further examined.

To enhance the exploitation of the RM sector, stake holders from the six ESEE countries proposed to pursue improvements in the following general fields: Upgrading the quality of geological potential data; promoting legislation reforms and codification; improving business environment, and human resources capacity building.

Given the significant mineral raw materials potential of the examined six ESEE countries and the interest already expressed for new mining projects in a number of these countries (e.g., SRB, MKD), for the RM Sector's sustainable development it is crucial to upgrade its environmental performance and introduce, if not already in place, sustainability and resource efficiency principles, in exploiting both PRMs and SRMs and managing the wastes.

Funding: This research was implemented in the frame of RESEERVE project (Project Number: 17029), funded by EIT RawMaterials, initiated and funded by the EIT (European Institute of Innovation and Technology).

Institutional Review Board Statement: Not applicable.

Informed Consent Statement: Not applicable.

Data Availability Statement: Publicly available datasets were analyzed in this study. This data can be found here: https:/ / reseerve.eu/results.

Acknowledgments: The authors of this article would like to thank for their support, and contribution in the evaluation of the RM sector the team of the Geological Survey of Slovenia, Coordinator of the RESEERVE Project and the Task Partners from the 6 ESEE countries. They would like to acknowledge the contribution of colleagues from the Geological Survey of Albania, the Geological Survey of Federation of Bosnia and Herzegovina, the Geological Survey of the Republic of Srpska, the Croatian Geological Survey, the University of Montenegro, the Ss. Cyril and Methodius University in Skopje, the Geological Survey of the Republic of Macedonia, and the University of Belgrade, as well as industrial stakeholders for their support.

Conflicts of Interest: The authors declare no conflict of interest. 


\section{References}

1. European Commission. The Raw Material Initiative-Meeting Our Critical Needs for Growth and Jobs in Europe; COM: Brussels, Belgium, 2008; p. 699. Available online: https:/ / eur-lex.europa.eu/LexUriServ /LexUriServ.do?uri=COM:2008:0699:FIN:en:PDF (accessed on 10 March 2021).

2. European Commission. Roadmap to a Resource Efficient Europe; COM: Brussels, Belgium, 2011; p. 0571. Available online: https:/ / eur-lex.europa.eu/legal-content/EN/TXT/?uri=CELEX:52011DC0571 (accessed on 14 March 2021).

3. Melcher, F.; Reichl, C. Economic Geology of the Eastern and South-eastern European (ESEE) Region. BHM Bergund Hüttenmännische Monatshefte 2017, 162, 238-244. [CrossRef]

4. SARMa Project: Home. Available online: http://www.sarmaproject.net/ (accessed on 3 March 2021).

5. Ris-Restore-Project. Available online: http:/ / ris-restore.zag.si / (accessed on 10 March 2021).

6. Results I RESEERVE. Available online: https:/ / reseerve.eu/results (accessed on 3 March 2021).

7. RESEERVE Project. Deliverable 6.3: SWOT and Gap analysis for the ESEE region. 2021; Unpublished report (Accessible for Project Partners).

8. INSPIRE Infrastructure for Spatial Information in Europe. Available online: https://inspire.ec.europa.eu/documents/Data Specifications/INSPIRE_DataSpecification_MR_v3.0_rc2.pdf (accessed on 8 April 2021).

9. RESEERVE Project. Deliverable 6.1: Mapping of the Available Business Opportunities in the ESEE Region. 2021. Available online: https:/ / reseerve.eu/deliverables\#d6-1-map-of-potential-business-cases-of-rm-sector-in-the-esee (accessed on 6 March 2021).

10. RESEERVE Project. Deliverable 6.2: Fact Sheet for the West Balkan Countries Status in Mining. 2020; Unpublished report (Accessible for Project Partners).

11. Doing Business. Available online: https://www.doingbusiness.org (accessed on 5 April 2021).

12. Reichl, C.; Schatz, M. World Mining Data. Minerals Production International Organizing Committee for the World Mining Congresses. 2021, pp. 1-268. Available online: https:/ /www.world-mining-data.info/wmd/downloads/PDF/WMD2021.pdf (accessed on 3 March 2021).

13. Reichl, C.; Schatz, M. World Mining Data. Minerals Production International Organizing Committee for the World Mining Congresses. 2020, pp. 1-265. Available online: https:/ /www.world-mining-data.info/wmd/downloads/PDF/WMD2020.pdf (accessed on 3 March 2021).

14. European Commission. Critical Raw Materials Resilience: Charting a Path towards Greater Security and Sustainability; COM: Brussels, Belgium, 2020; p. 474. Available online: https:/ / eur-lex.europa.eu/legal-content/EN/TXT/?uri=CELEX:52020DC0474 (accessed on 10 March 2021).

15. RESEERVE Project. Deliverable 3.2: Report on the Evaluation of the PPM Database. 2019; Unpublished report (Accessible for Project Partners).

16. Country Summaries-European Commission. Available online: https://ec.europa.eu/assets/jrc/minventory/countrysummaries19b4.html? country=Croatia (accessed on 3 March 2021).

17. Jelenković, R.; Kostić, A.; Životić, D.; Ercegovac, M. Mineral resources of Serbia. Geol. Carpath 2008, 59, 345-361.

18. European Bank for Reconstruction and Development. Extractive Mining Industries Strategy 2018-2022. 2017. Available online: https:/ / www.ebrd.com/mining\%20operations\%20policy.pdf (accessed on 3 March 2021). 